\title{
Thermal evaluation of MAG/TIG welding using numerical extension tool
}

\author{
Eduardo Marques ${ }^{1,2 *}$, Alexandre Pereira ${ }^{1}$, João Ribeiro ${ }^{2,3}$ \\ ${ }^{1}$ Mechanical Engineering Department, Federal Center for Technological Education \\ (CEFET/RJ) 522, Rua do Areal., Angra dos Reis, Rio de Janeiro 23953-030, Brazil \\ ${ }^{2}$ Deptartment of Mechanical Technology, Polytechnic Institute of Bragança (IPB) \\ Campus de Santa Apolónia, Bragança 5300-253, Portugal \\ ${ }^{3}$ Sustainable Processes and Products, Mountain Research Center (CIMO) Campus de \\ Santa Apolónia, Bragança 5300-253, Portugal
}

\section{OPEN ACCESS}

Received: January 5, 2021

Revised: May 13, 2021

Accepted: July 8, 2021

\section{Corresponding Author:}

Eduardo Marques

eduardo.dc.marques@alunos.ipb.

pt

\section{Copyright: The Author(s).} This is an open access article distributed under the terms of the Creative Commons Attribution License (CC BY 4.0), which permits unrestricted distribution provided the original author and source are cited.

\section{Publisher:}

Chaoyang University of

Technology

ISSN: 1727-2394 (Print)

ISSN: 1727-7841 (Online)

\begin{abstract}
The manufacturing processes involving thermal transitions have been more used in industries nowadays, being the welding one of the most widely used. The requirement to design and predict adverse conditions are fundamental to the development of any mechanical project. As a result, the market needs have motivated the companies to find faster and more effective solutions, being one of a recent tools an ACT (Ansys Customization Toolkit) called "Moving Heat Source", in which is executed the Gaussian heat source to model welding and laser processes. Based on this, the present work proposes to evaluate the accuracy of that extension implementing a finite element model for the MAG/TIG welding processes in DINCK20 steel and Al6082-T6 aluminium alloy, comparing with one of the first mathematical model proposed by the literature (Rosenthal) and with a recent analytical method of high precision already validated experimentally. The results showed a smaller global error for MAG process $(3 \sim 10 \%)$ when compared to TIG $(15 \sim 18 \%)$ and, the temperatures measured on the surface of the plate presented errors lower than the bottom in both alloys.
\end{abstract}

Keywords: Numerical extension, Moving heat source, Finite element, Analytical method.

\section{INTRODUCTION}

Nowadays, industries have increased manufacturing processes that involves thermal transitions of which several welding techniques are popular such as GTAW (Gas Tungsten Arc Welding), GMAW (Gas Metal Arc Welding), laser and others (Bajpei et al., 2016; Kik and Górka, 2019; Kumar and Sinha, 2018; Winczek, 2017; Zuo et al., 2020). These technologies are widely used in industries to assemble various products such as automobiles, trains, ships, and bridges (Deng et al., 2007).

Among the welding methods, the most commons in the industrial sector are Metal Active Gas (MAG) for steel (Guilherme et al., 2020) and Tungsten Inert Gas (TIG) for stainless steel and aluminium alloys (ASM, 1993; Bansal et al., 2020). That processes when the welding starts, the heat source is focus in a region where the materials are locally casting and joint (Wang et al., 2020), consequently, this local heat creates nonuniform thermal cycles in the materials (Darmadi et al., 2014).

Nevertheless, the thermal non-uniformity has consequences of the material equilibrium stress-strain state, that can lead to residual stresses (Knoedel et al., 2017), fatigue failures (Lahtinen et al., 2019), stress corrosion and fracture (Vicente et al., 2018). One of the first steps to avoid such problems is the understanding of thermal phenomena, that affect the structure at macro and micro-structural levels, where is presenting by Fig. 1 and Fig. 2 the welding thermal changes for steel and aluminium alloy. 


\section{International Journal of Applied Science and Engineering}

Marques et al., International Journal of Applied Science and Engineering, 18(5), 2021006

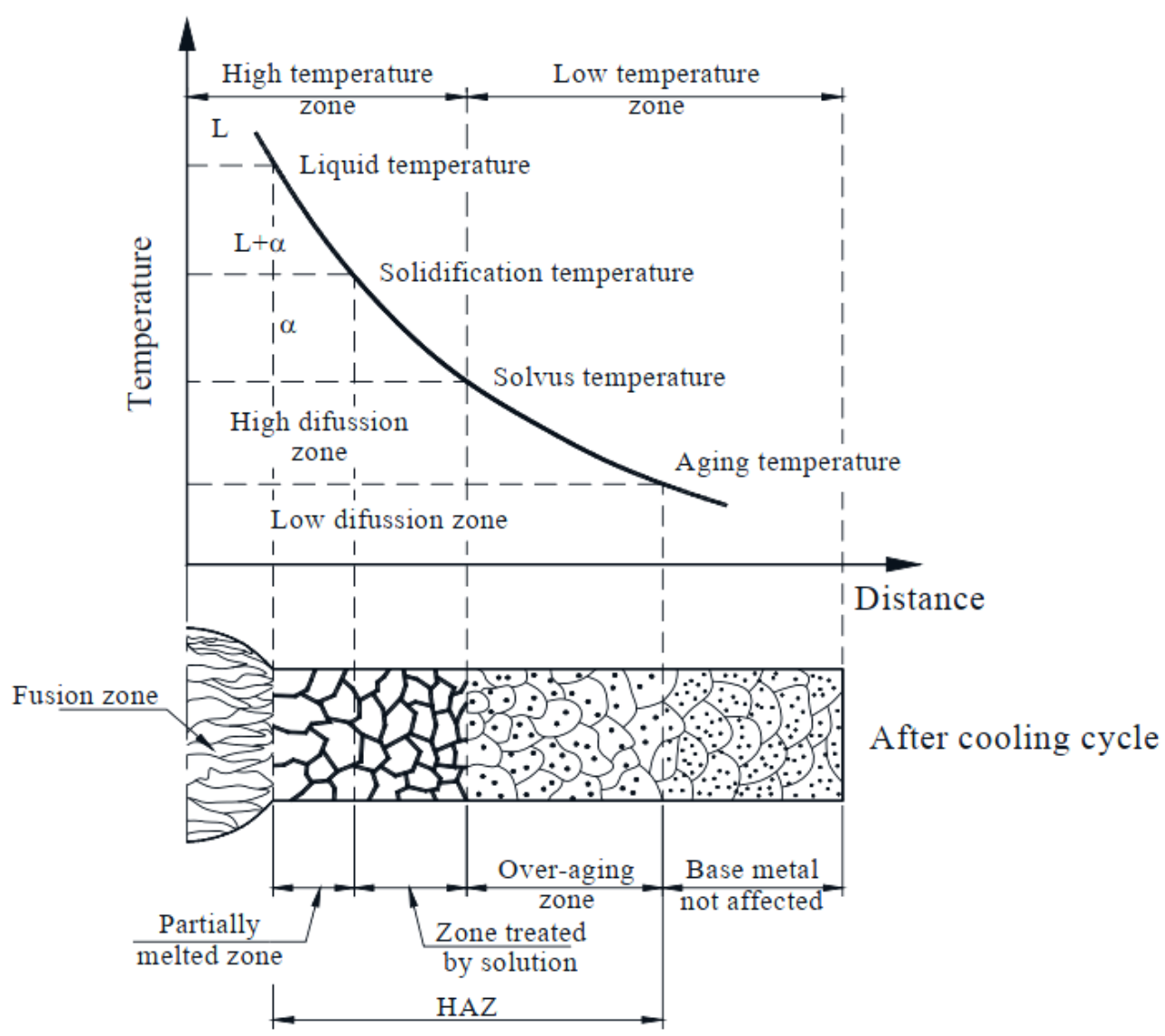

Fig. 1. Schematic representation of microstructural transformations for aluminium alloys, image gently authorized by the authors (Ambriz and Jaramillo, 2014)

Typically, there are three types of approaches to interpret this behaviour, such as analytical (Nasiri and Enzinger, 2019), numerical (Balram and Rajyalakshmi, 2019) and experimental (Kumar et al., 2020).

With the growing development of computer software and hardware in recent years, Finite Element Methods (FEM) has become an essential instrument in computational studies (Wang et al., 2019). The vantage of FEM is the lower cost and time associated when compared to experimental methods (Chiocca et al., 2019; Kik and Górka, 2019).

Meanwhile, it is not always a simple task to perform a finite element transient thermal simulation, for this purpose, simplifications are often introduced (Asserin et al., 2011). Effects of heat conduction and convection characterize these types of problems, resulting from an applied moving heat source. Throughout history, researchers have been studied this phenomenon, with Rosenthal (1946), where proposed a quasi-steady state analytical solution on a semiinfinite body for thick or thin plates with constant material properties.
After this, Friedman (1975) proposed a numerical solution, in which apply a Gaussian distribution of the heat source applied to finite elements. Goldak et al. (1984) presented a numerical solution in the form of a semiellipsoidal and double-ellipsoidal heat source, and many other researchers contributed to the area, just as, Komanduri and Hou (2000); Nguyen et al. (1999); Darmadi (2011) for example.

In Nasiri and Enzinger (2019), proposed an analytical solution for heating flux in welding called adaptive function. They measured temperature values close to the melting line and found an overall relative error of less than 5\% concerning the experimental method.

In literature review, it was possible to observe studies of the thermal distribution using finite elements with the most diverse techniques, such as element birth and death (Amudha et al., 2019), Goldak's 3D ellipsoidal functions (Velaga and Ravisankar, 2017) and using other similar simulation software like SYSWELD (Ganesh et al., 2014). 
Marques et al., International Journal of Applied Science and Engineering, 18(5), 2021006

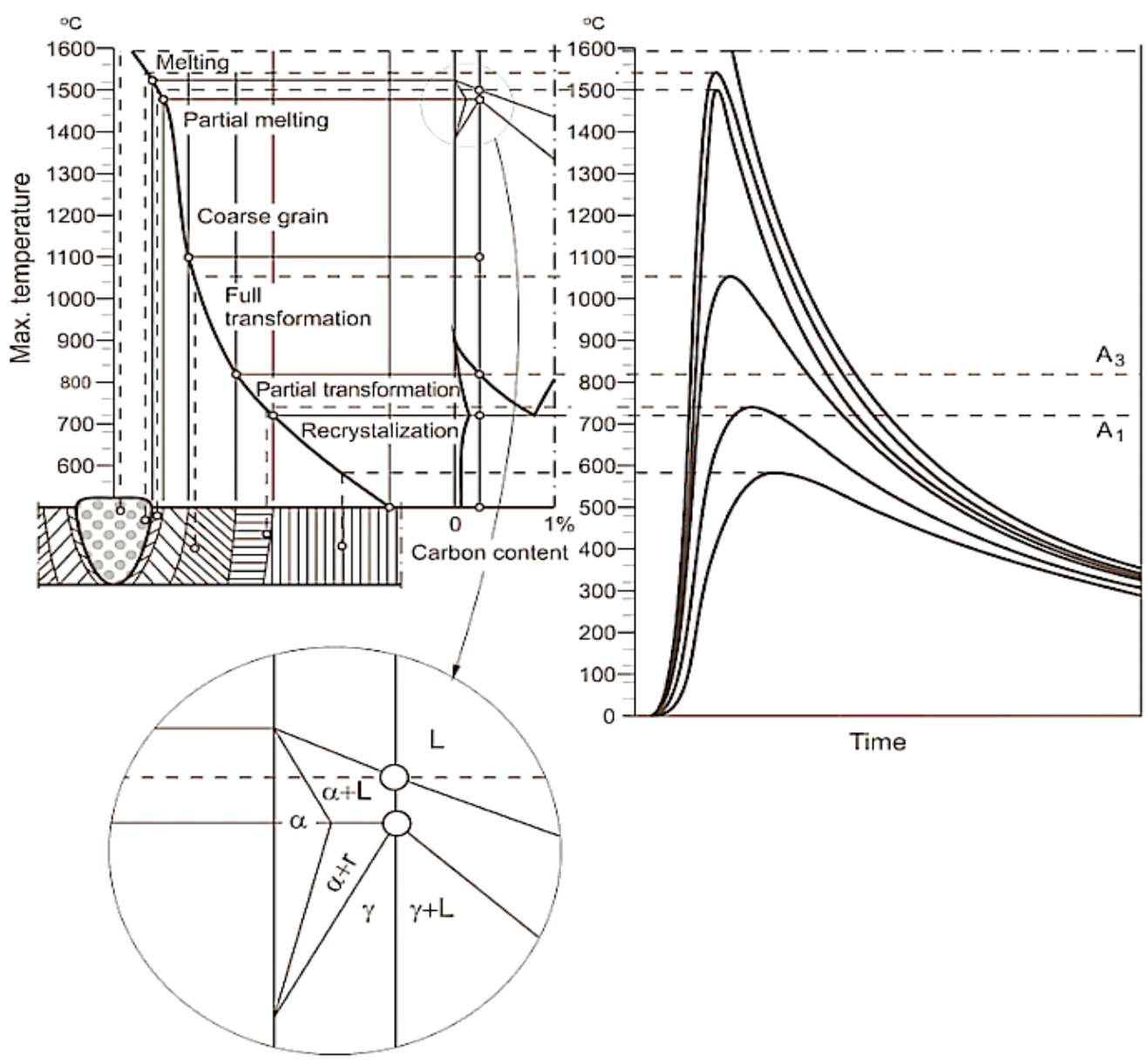

Fig. 2. Schematic representation of microstructural transformations for low carbon steel alloys, image gently authorized by the authors (Winczek, 2017)

However, there is not much information about studies using an extension tool for numerical simulation. Ansys Customization Toolkit (ACT) simplifies the simulation features of workbench interface, that previously was only possible through inserting Mechanical Ansys Parametric Design Language (MAPDL) commands, and compresses your simulation process (Ansys, 2020). Ansys ${ }^{\circledR}$ has demonstrated that this tool has helped some companies to develop efficient solutions in their products (Cezario et al., 2014).

In 2017, the company launched an ACT extension called Moving Heat Source (MHS), whose function is to model a moving gaussian heat source for thermal distribution, to make simulations involving welding and laser cutting processes more straightforward (Cezario et al., 2014). In the past, modeling this type of MHS was time-consuming and required creating custom commands (Ansys, 2020).

Based on this, the present study aims to evaluate the FEM ACT extension by comparing the simulation results with a recently analytical method (Nasiri's adaptive function) and classical literature analytical method (Rosenthal's) in Matlab. The analysis considered four points close to the melt line, both on surface and at the bottom of welded piece, also, a steel DINCK20 and aluminum 6082-T6 alloys were used for the study. The choice of these alloys is based on the fact that the DIN CK20 steel alloy is one of the most common and studied in the literature, thus having welldefined thermal properties. Al6082-T6 aluminum alloy on the other hand, belongs to the $6 \mathrm{xxx}$ series family that is one of the most popular within the industries. With the results, it is expected that the numerical extension tool helps to reduce the time and complexities of thermal welding simulations, even more in industrial solutions, where is search less cost and time involved.

\section{MATERIALS AND METHODS}

\subsection{Rosenthal Analytical Solution}

In the electric arc, the heat introduced into the fusion pool is transported by convection and thermal conduction (Feng, 2005). The heat conduction equation from the energy conservation law for moving heat source (Kumar and Sinha, 2018; Nasiri and Enzinger, 2019; Venkatkumar and Ravindran, 2019) is given by Equation (1):

$\rho c\left(\frac{\partial T}{\partial t}+v \cdot \nabla T\right)=\nabla(k \cdot \nabla T)+\dot{Q}$ 


\section{International Journal of Applied Science and Engineering}

Marques et al., International Journal of Applied Science and Engineering, 18(5), 2021006

Where, $\rho$ is density $\left(\mathrm{kg} / \mathrm{m}^{3}\right), c$ is the specific heat $(\mathrm{J}$ $\left./ \mathrm{kg} \cdot{ }^{\circ} \mathrm{C}\right), T$ is the temperature $\left({ }^{\circ} \mathrm{C}\right)$, $\mathrm{t}$ is the time, $v$ is the welding speed $(\mathrm{m} / \mathrm{s}), k$ is the thermal conductivity $\left(\mathrm{W} / \mathrm{m} \cdot{ }^{\circ} \mathrm{C}\right)$ and $Q$ is the heat flow $(\mathrm{W} / \mathrm{s})$.

From Equation (1), Rosenthal used some assumptions to derive the analytical solution, which are; (i) Heat flow at steady state; (ii) a point source of heat; (iii) constant thermal properties; (iv) negligible melting heat; (v) no thermal losses on the surface; (vi) no thermal convection in the fusion pool. Thus, the final equation form founded is presented according to Equation (2):

$T=T_{0}+\frac{Q}{2 \pi k R} e^{\left[\frac{-\rho c v}{2 k}(R+\xi)\right]}$

Where, $T_{0}$ is the initial temperature $(\mathrm{K}), Q$ the heat flow (W) $R$ is the heat source distance presented by the Equation (3), $\xi$ is the relation for the relative coordinate as a function of time for the quasi-stationary state according to Equation (4):

$R=\sqrt{x^{2}+\xi^{2}+z^{2}}$

$\xi=y-v \cdot t$

\subsection{Adaptive Function Solution}

The solution proposed by Nasiri and Enzinger is based on the development of a function that can measure temperatures close to the fusion line, through geometric parameters of the weld pool. The first step of the solution is to approximate $R$ to an ellipsoidal function $R_{p}$, presented by Equation (5):

$R_{p}=\sqrt{\left(\frac{x}{a_{m}}\right)^{2}+\left(\frac{\xi}{b_{m}}\right)^{2}+\left(\frac{z}{c_{m}}\right)^{2}+d_{m}^{2}}$

(a)

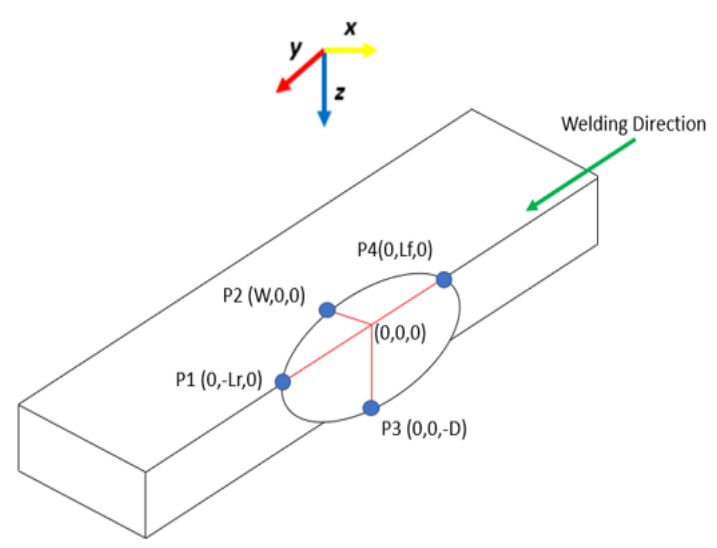

The parameters $a_{m}, b_{m}, c_{m}$ and $d_{m}$ are calculated using information about the melt pool geometry, in which they are represented through points $\mathrm{P} 1, \mathrm{P} 2, \mathrm{P} 3$ and $\mathrm{P} 4$ according to Fig. 3(a). The dimensions of the base material and the welding direction are shown by Fig. 3 (b).

In addition, the deductions for these geometric parameters are presented according to Equation (6) to (9). The variables $L_{f}$ and $L_{r}$ are geometric parameters taken from the melt pool and, parameter $B$ is a dimensionless factor presented in Nasiri's final equation.

$a_{m}=\frac{W}{\sqrt{\left[\frac{e^{-B W}}{\left(T_{m}-T_{0}\right)}\right]^{2}-d_{m}^{2}}}$
$b_{m}=\frac{L_{f}}{\sqrt{\left[\frac{e^{-2 B L_{f}}}{\left(T_{m}-T_{0}\right)}\right]^{2}-d_{m}^{2}}}$
$c_{m}=\frac{D}{\sqrt{\left[\frac{e^{-B D}}{\left(T_{m}-T_{0}\right)}\right]^{2}-d_{m}^{2}}}$
$d_{m}=\frac{1}{\left(T_{m}-T_{0}\right)} \sqrt{\frac{\left(e^{-2 B L_{f}}\right)^{2}-\left(\frac{L_{f}}{L_{r}}\right)^{2}}{1-\left(\frac{L_{f}}{L_{r}}\right)^{2}}}$

Nevertheless, for an exact correspondence between the function and the fusion line, a dimensionless parameter $\omega$ is necessary to cause the adaptation of the function $f$. The parameter $\omega$ changes the scale from normal length to a scale in fusion pool dimensions and is expressed by the proportion of the coordinate of the point of interest. Equation (10) shows how this parameter can be defined.

$\omega_{x}=\frac{x}{W} ; \omega_{\xi f}=\frac{\xi}{L_{f}} ; \omega_{\xi r}=\frac{\xi}{L_{r}} ; \omega_{z}=\frac{z}{D}$

(b)

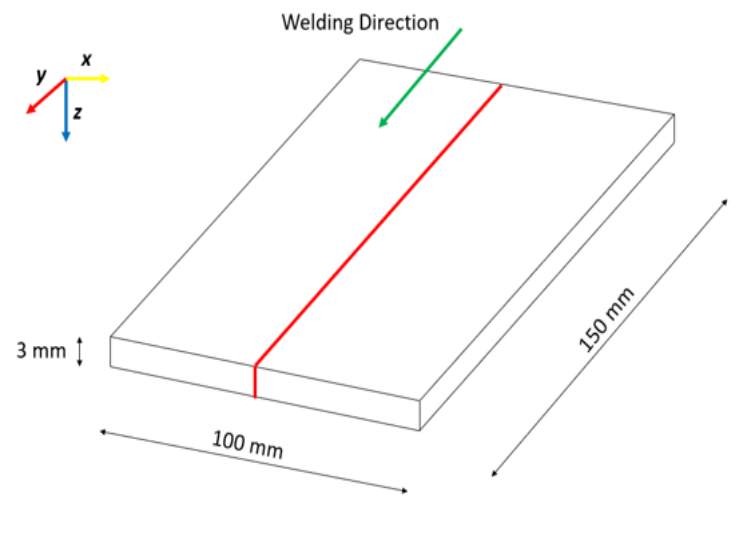

Fig. 3. (a) Geometric parameters (b) Schematic dimensions and weld direction 


\section{International Journal of Applied Science and Engineering}

Marques et al., International Journal of Applied Science and Engineering, 18(5), 2021006

Another important factor is that the modification function must be equal to 1 at any point in the fusion line, this will not change the fusion isotherm, this is defined by means of $\omega= \pm 1$. So, the modification function is given by Equation (11) and the final modification function is shown according to Equation (12).

$f( \pm 1)=1$

$f(\omega)=\left(M \omega^{2}-M \sqrt{\omega^{2}}+1\right)^{N}$

The values of $M$ and $N$ are stipulated through initial parameters, thus in this way, causing the adaptation of the function, in order to clarify how the algorithm is performed, Fig. 4 shows how the iterative method works. Then, the final form of the adaptive function is presented according to Equation (13) and (14):

\subsection{Input Data for Analytical Solutions}

For this investigation, DIN CK20 steel and 6082-T6 aluminium alloy were used, that in Table 1 is present the input data. The software used was Matlab ${ }^{\circledR}$ R2018.a, in a computer with AMD A9-9410 RADEON R5 5 Core $2 \mathrm{C}+3$ $\mathrm{G}$ processor at $2.90 \mathrm{GHz}$ and a total RAM memory of $8 \mathrm{~GB}$.

The parameter $\mathrm{B}$ is a dimensionless factor presented in Nasiri and Enzinger final equations, $Q$ is the heat amount in
(W) necessary to cause the melt of the addition metal during the welding process, Tm is the melting temperature of the material in $\left({ }^{\circ} \mathrm{C}\right), \eta$ is the welding efficiency and $t$ is the time interval in (s).

To evaluate the numerical simulation, 4 points were defined next to the weld pool, where is presented by Fig. 5. The geometrical parameters used were, $\mathrm{W}=5 \mathrm{~mm}$, Lf $=$ $2.5 \mathrm{~mm}, \mathrm{Lr}=-7.5 \mathrm{~mm}$ e $\mathrm{D}=-3 \mathrm{~mm}$, these values correspond to a welding pass.

Table 2 shows the values for the variables $\mathrm{M}, \mathrm{Nx}$, Nef, Ner and $\mathrm{N}$ during the calculation of thermal distribution for the DIN CK20 and the Al6082-T6.

\subsection{Finite Element Solution}

The welding simulation was performed using the ACT extension moving heat source, in which DIN CK20 steel and Al6082-T6 were used as the base materials for simulation. The thermal properties for the FEM are presented by the Fig. 6, that the equations for steel were obtained from Eurocode 1993-1-2 (2005, 2005) (Design of Steel Structures - Verification of Fire Resistance) and for Aluminium, Eurocode 1999-1-2 (2007, 2007) (Design of Aluminium Structures - Structural Fire Design).

$$
\begin{aligned}
& T=T_{0}+\frac{1}{\sqrt{\left(f\left(\frac{x}{W}\right) \cdot \frac{x}{a_{m}}\right)^{2}+\left(f\left(\frac{\xi}{L_{f}}\right) \cdot \frac{\xi}{b_{m}}\right)^{2}+\left(f\left(\frac{z}{D}\right) \cdot \frac{z}{c_{m}}\right)^{2}+d_{m}}} e^{-B(R+\xi)} \\
& T=T_{0}+\frac{1<0,}{\sqrt{\left(f\left(\frac{x}{W}\right) \cdot \frac{x}{a_{m}}\right)^{2}+\left(f\left(\frac{\xi}{L_{r}}\right) \cdot \frac{\xi}{b_{m}}\right)^{2}+\left(f\left(\frac{z}{D}\right) \cdot \frac{z}{c_{m}}\right)^{2}+d_{m}}} e^{-B(R+\xi)}
\end{aligned}
$$

Table 1. Matlab input data for MAG/TIG welding and alloys

\begin{tabular}{ccc}
\hline Variables & $\mathrm{DIN} \mathrm{CK} 20$ & $\mathrm{Al} 6082-\mathrm{T} 6$ \\
\hline$\rho$ & $7870 \mathrm{~kg} / \mathrm{m}^{3}$ & $2710 \mathrm{~kg} / \mathrm{m}^{3}$ \\
$c_{p}$ & $420 \mathrm{~J} / \mathrm{kg} \cdot{ }^{\circ} \mathrm{C}$ & $935 \mathrm{~J} / \mathrm{kg}{ }^{\circ} \mathrm{C}$ \\
$k$ & $47 \mathrm{~W} / \mathrm{m} \cdot{ }^{\circ} \mathrm{C}$ & $174 \mathrm{~W} / \mathrm{m}^{\circ} \mathrm{C}$ \\
$T_{0}$ & $22{ }^{\circ} \mathrm{C}$ & $2{ }^{\circ} \mathrm{C}$ \\
$T_{m}$ & $1410{ }^{\circ} \mathrm{C}$ & $575^{\circ} \mathrm{C}$ \\
$v$ & $2.5 \mathrm{e}-3 \mathrm{~m} / \mathrm{s}$ & $2.5 \mathrm{e}-3 \mathrm{~m} / \mathrm{s}$ \\
$B$ & $\left(\rho \cdot c_{p} \cdot v\right) / 2 \cdot k$ & $\left(\rho \cdot c_{p} \cdot v\right) / 2 \cdot k$ \\
$\eta$ & 0.7 & 0.7 \\
$I$ & $110 \mathrm{~A}$ & $120 \mathrm{~A}$ \\
$V$ & $22.8 \mathrm{~V}$ & $13.3 \mathrm{~V}$ \\
$Q$ & $\eta \cdot \mathrm{V} \cdot \mathrm{I}$ & $\eta \cdot \mathrm{V} \cdot \mathrm{I}$ \\
$t$ & {$[0: 0.4: 60] \mathrm{s}$} & {$[0: 0.4: 60] \mathrm{s}$} \\
\hline
\end{tabular}

Table 2. Matlab input data for $\mathrm{M}$ and $\mathrm{N}$ variables

\begin{tabular}{cccccc}
\hline Material & $\mathrm{M}$ & $N_{x}$ & $N_{e f}$ & $N_{e r}$ & $N$ \\
\hline DINCK20 & 0.45 & 0.45 & -0.25 & -0.22 & -0.9 \\
A16082-T6 & 0.01 & 0.45 & -0.55 & -0.22 & -0.9 \\
\hline
\end{tabular}




\section{International Journal of Applied Science and Engineering}

Marques et al., International Journal of Applied Science and Engineering, 18(5), 2021006

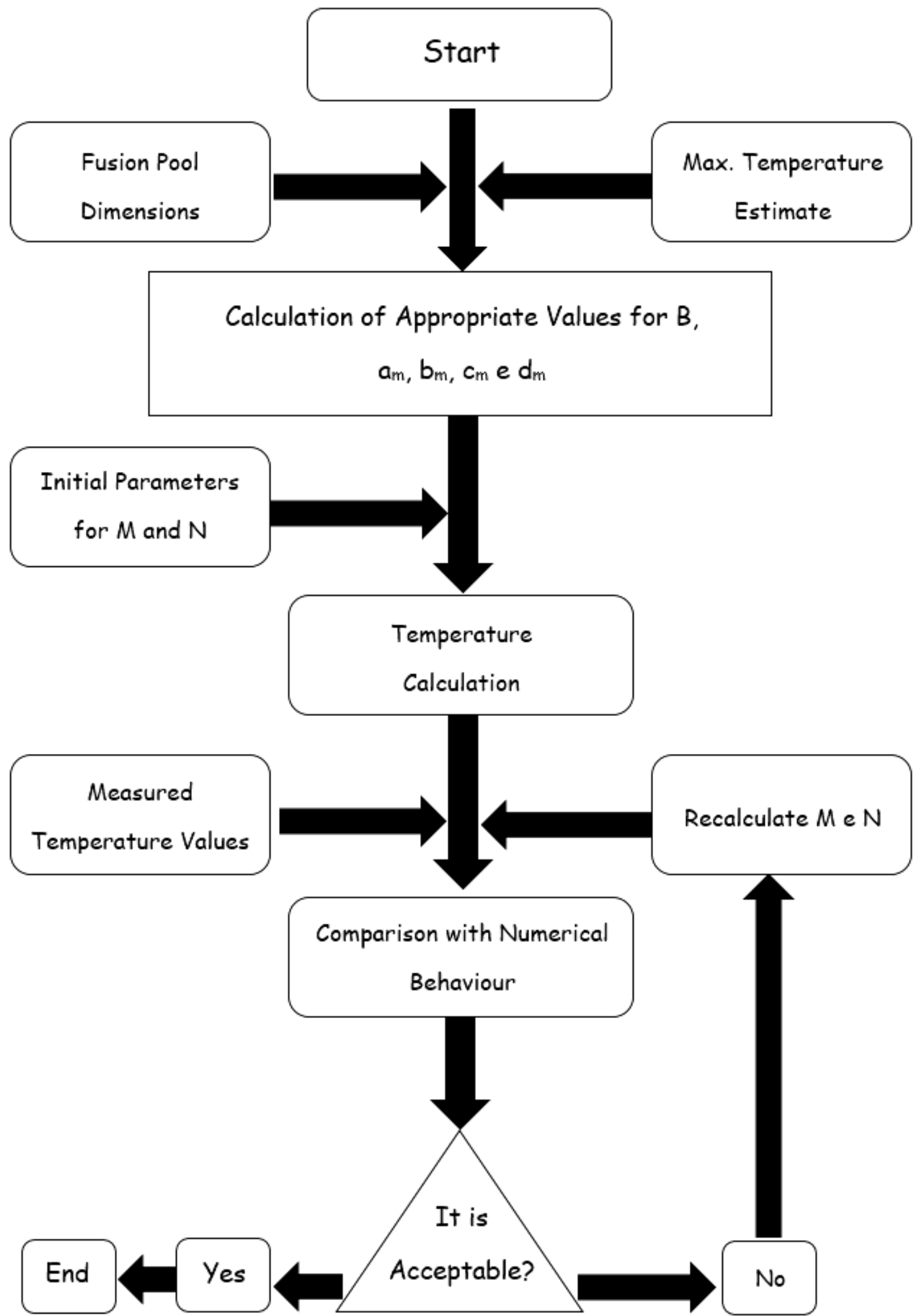

Fig. 4. Adaptive function iteration flowchart in matlab 


\section{International Journal of Applied Science and Engineering}

Marques et al., International Journal of Applied Science and Engineering, 18(5), 2021006

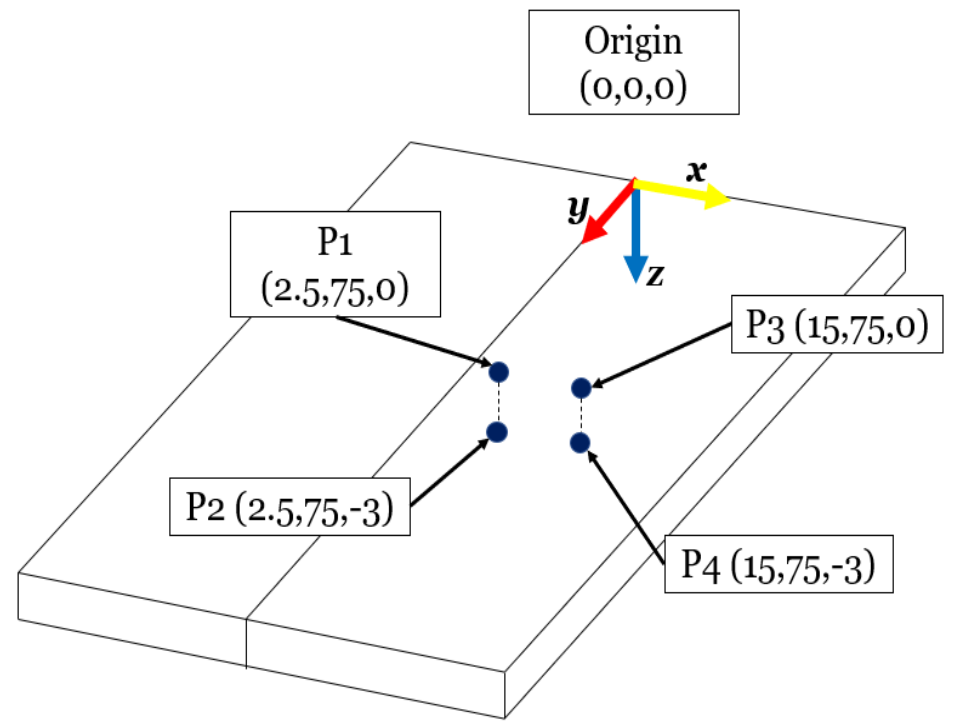

Fig. 5. Illustration of the 4 points studied in the analytical-numerical comparison

\section{DIN CK20}
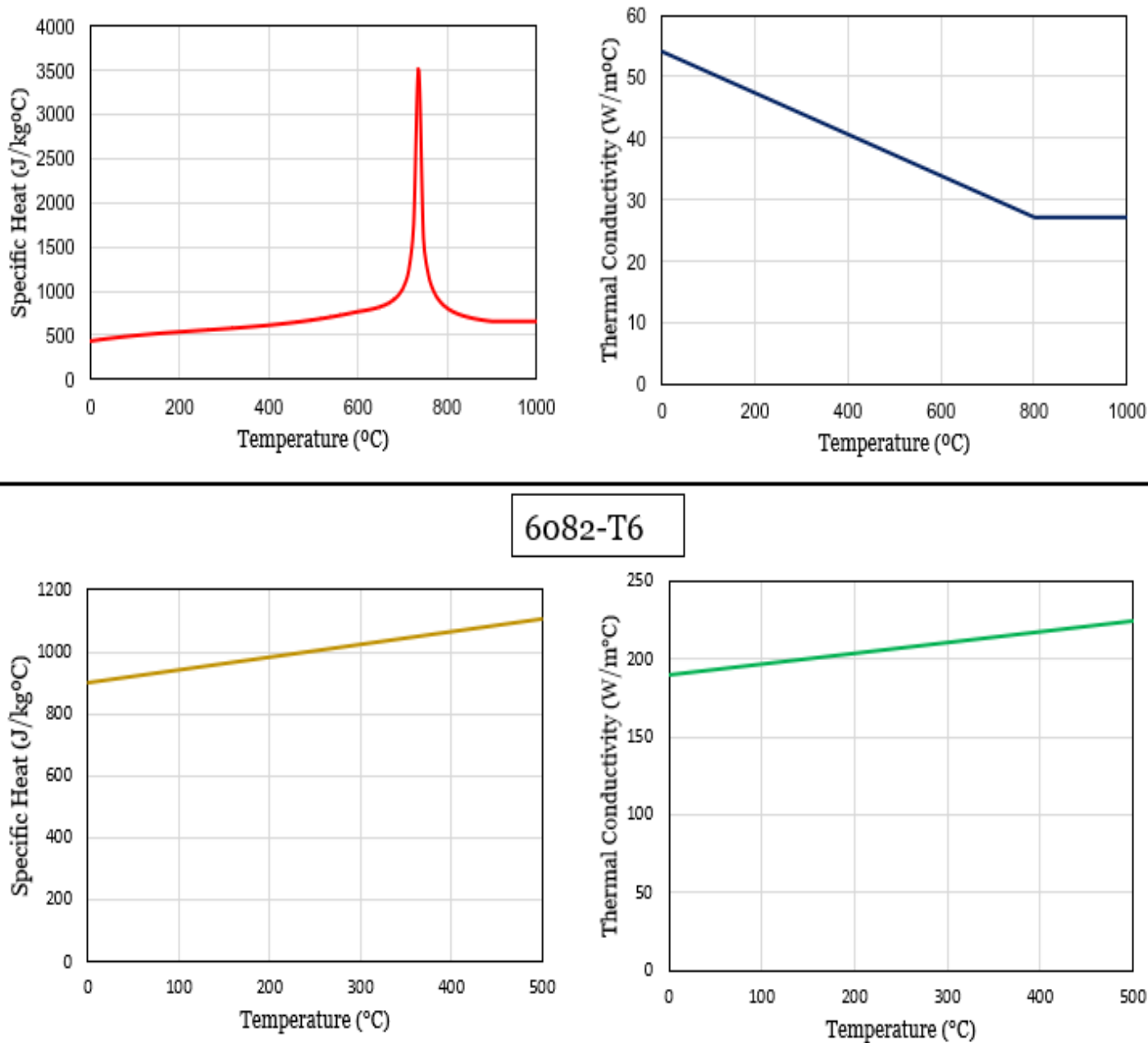

6082-T6

Fig. 6. Thermal conductivity and specific heat for DIN CK20 and 6082-T6 alloys 


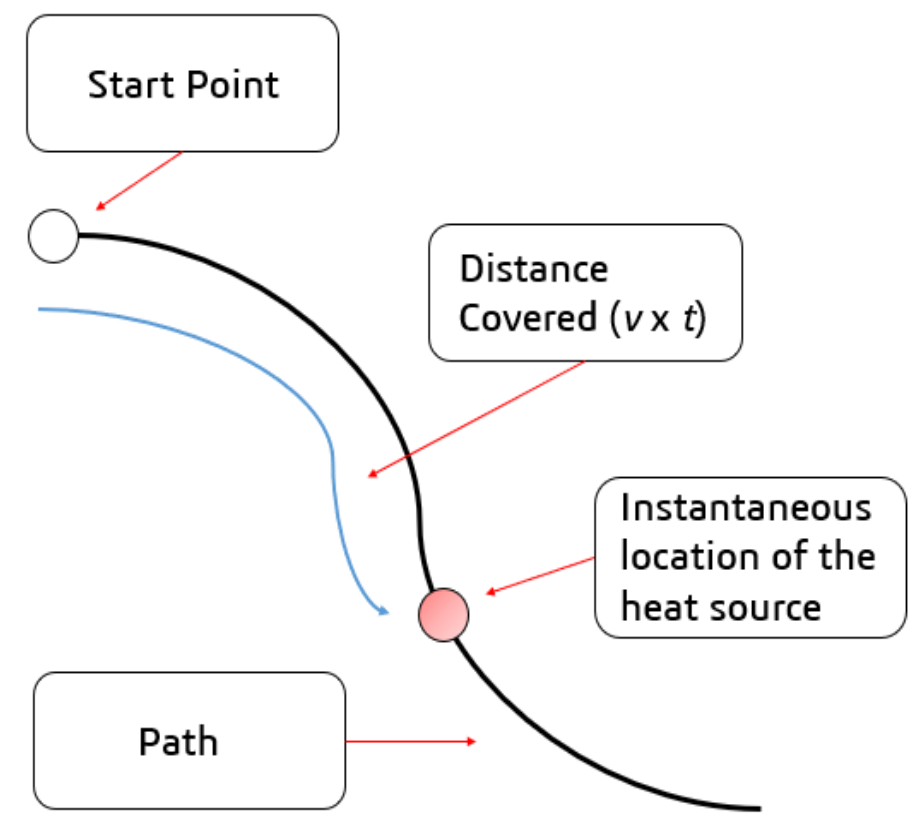

Fig. 7. Illustration of the moving heat flux calculation performed by the ACT extension

Table 3. Input data for ACT moving heat source

\begin{tabular}{ccc}
\hline & $\mathrm{MAG}$ & TIG \\
\hline Velocity & $2.5 \mathrm{~mm} / \mathrm{s}$ & $2.5 \mathrm{~mm} / \mathrm{s}$ \\
Electric Beam Radius & $5 \mathrm{~mm}$ & $5 \mathrm{~mm}$ \\
Source Power Intensity & $23 \mathrm{~W} / \mathrm{mm}^{2}$ & $14 \mathrm{~W} / \mathrm{mm}^{2}$ \\
Time & $60 \mathrm{~s}$ & $60 \mathrm{~s}$ \\
Melting Temperature & $1410^{\circ} \mathrm{C}$ & $575^{\circ} \mathrm{C}$ \\
Number of Subdivisions & 150 & 150 \\
Minimum Subdivision for Cooling & 15 & 15 \\
\hline
\end{tabular}

Table 4. Mesh refinement by simulation

\begin{tabular}{ccc}
\hline Simulation & Element Dimension for Base Material & Element Dimension for Weld Pool \\
\hline S1 & $5 \mathrm{~mm}$ & $2 \mathrm{~mm}$ \\
S2 & $2.5 \mathrm{~mm}$ & $1 \mathrm{~mm}$ \\
S3 & $1 \mathrm{~mm}$ & $0.5 \mathrm{~mm}$ \\
\hline
\end{tabular}

The extension feature provides two types of solutions: (1) moving heat flux and (2) moving heat energy. For this research, it was used moving heat flux, due to the variable inputs being known welding parameters, such as speed, welding radius, and heat flow. The mathematical formulation of (1) is presented by the Equation (15):

$q=P \cdot e^{-\frac{\left[\left(x-x_{0}\right)^{2}+\left(y-y_{0}\right)^{2}+\left(z-z_{0}\right)^{2}\right]}{r^{2}}}$

Where $q$ is the heat flow on the surface, $P$ is the intensity power of the heat source $\left(\mathrm{W} / \mathrm{mm}^{2}\right), r$ is the radius of the beam $(\mathrm{mm}),\left(x_{0}, y_{0}, z_{0}\right)$ it is the instantaneous position of the heat flow in the path given by the product of the speed of the heat flow and time.

The interface performs the calculation according to the image shown in Fig. 7, in which a point is defined as the beginning, a path (so that the welding is developed) as a function of the welding speed $v$ and time $t$.

The element used in the simulation was SURF152 with 4 nodes with three degrees of freedom and the input data for the numerical simulation are presented according to Table 3. To evaluate the mesh convergence during the simulation, three different meshes refinements were proposed, they are presented according to the Table 4 and Fig. 8.

The boundary condition is a tabular data temperature versus convection coefficient (stagnant air - horizontal cycle) presented by Fig. 9 .

The machine used for simulations presents an AMD EPYC 7351 16-core processor with 16 CPUs with $2.4 \mathrm{GHz}$ and $16 \mathrm{~GB}$ of memory. The version of FEM software is Ansys 2019 R3 -Academic Research Mechanical and CFD. 


\section{International Journal of Applied Science and Engineering}

Marques et al., International Journal of Applied Science and Engineering, 18(5), 2021006
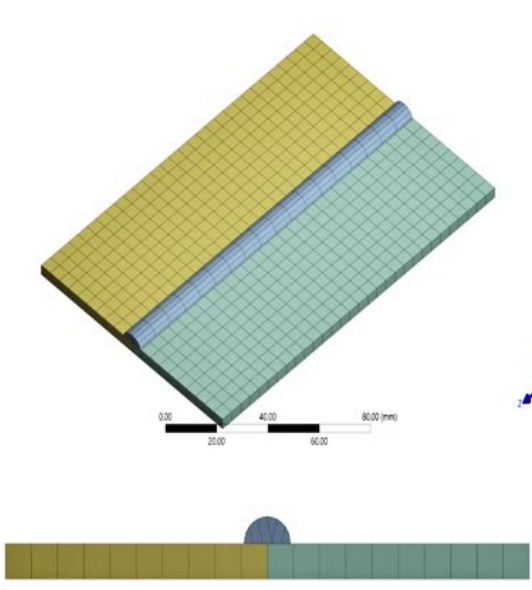

S1
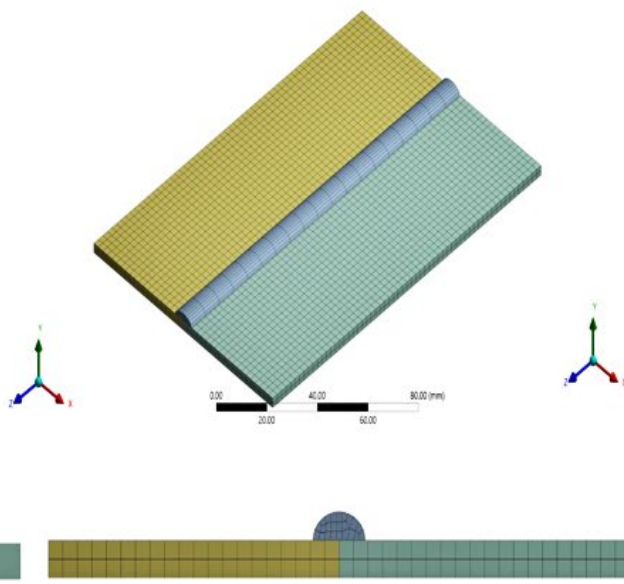

S2
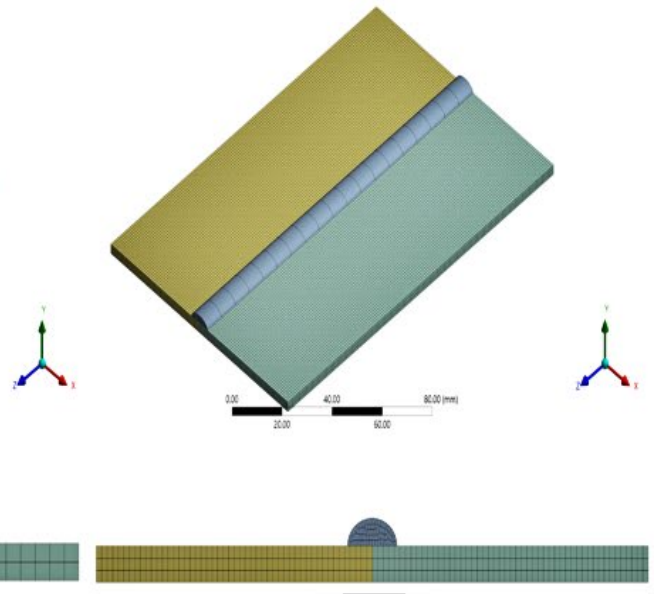

S3

Fig. 8. Finite element mesh for the three refinements

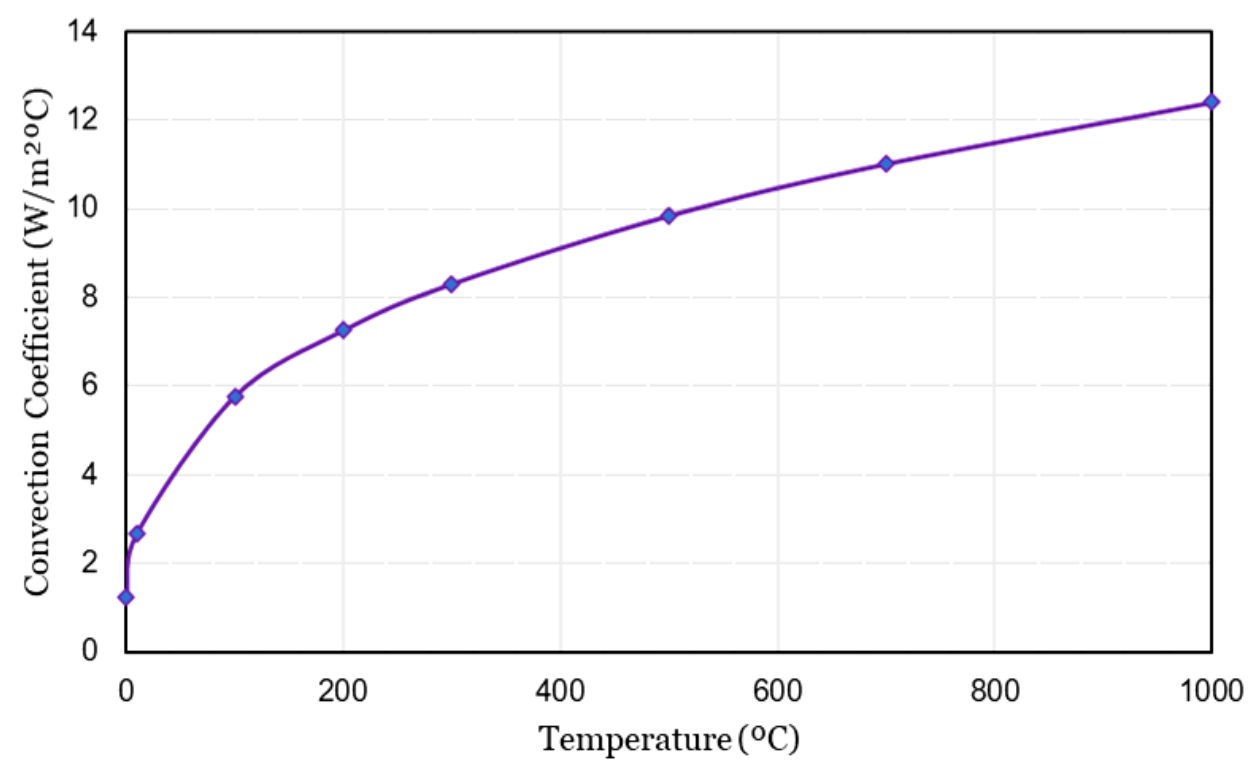

Fig. 9. Convection coefficient (stagnant air - horizontal cycle)

Table 5. Time and memory elapsed for transient thermal simulations

\begin{tabular}{cccc}
\hline & $\mathrm{S} 1$ & $\mathrm{~S} 2$ & $\mathrm{~S} 3$ \\
\hline Simulation Time & $\sim 45 \mathrm{~s}$ & $\sim 84 \mathrm{~s}$ & $\sim 786 \mathrm{~s}$ \\
Memory Used & $558 \mathrm{MB}$ & $740 \mathrm{MB}$ & $2753 \mathrm{MB}$ \\
\hline
\end{tabular}

\section{RESULTS AND DISCUSSION}

\subsection{Mesh Refinements}

The results of the computation time and total memory used in the numerical simulations is presented in Table 5, where it is shown that the S3 was the most time demanded (around 13 minutes).

In Fig. 10, is displayed the time temperature evolution for MAG process. S1 presented an average temperature distribution lower than the other refinements, around $1748^{\circ} \mathrm{C}$, an inverse situation for $\mathrm{S} 2$, with values above $2040^{\circ} \mathrm{C}$.
The S3 presented a value in the midst of $\mathrm{S} 1$ and $\mathrm{S} 2$, with a medium temperature of $1836^{\circ} \mathrm{C}$. Furthermore, it exhibited a more refinement behaviour than the other curves, in other words, the best-suited mesh for the study.

The maximum temperature values for each simulation (S1, S2 and S3) were respectively, $2166^{\circ} \mathrm{C}, 2567^{\circ} \mathrm{C}$ and $2376^{\circ} \mathrm{C}$. These data are important in welding practices situations, due the highest temperature parameter reached be a crucial value for sizing project.

For the TIG solution, the results are present according to the Fig. 11, where the temperature is a medium of $660^{\circ} \mathrm{C}$ and again it was verified that the $\mathrm{S} 3$ simulation showed the 


\section{International Journal of Applied Science and Engineering}

Marques et al., International Journal of Applied Science and Engineering, 18(5), 2021006

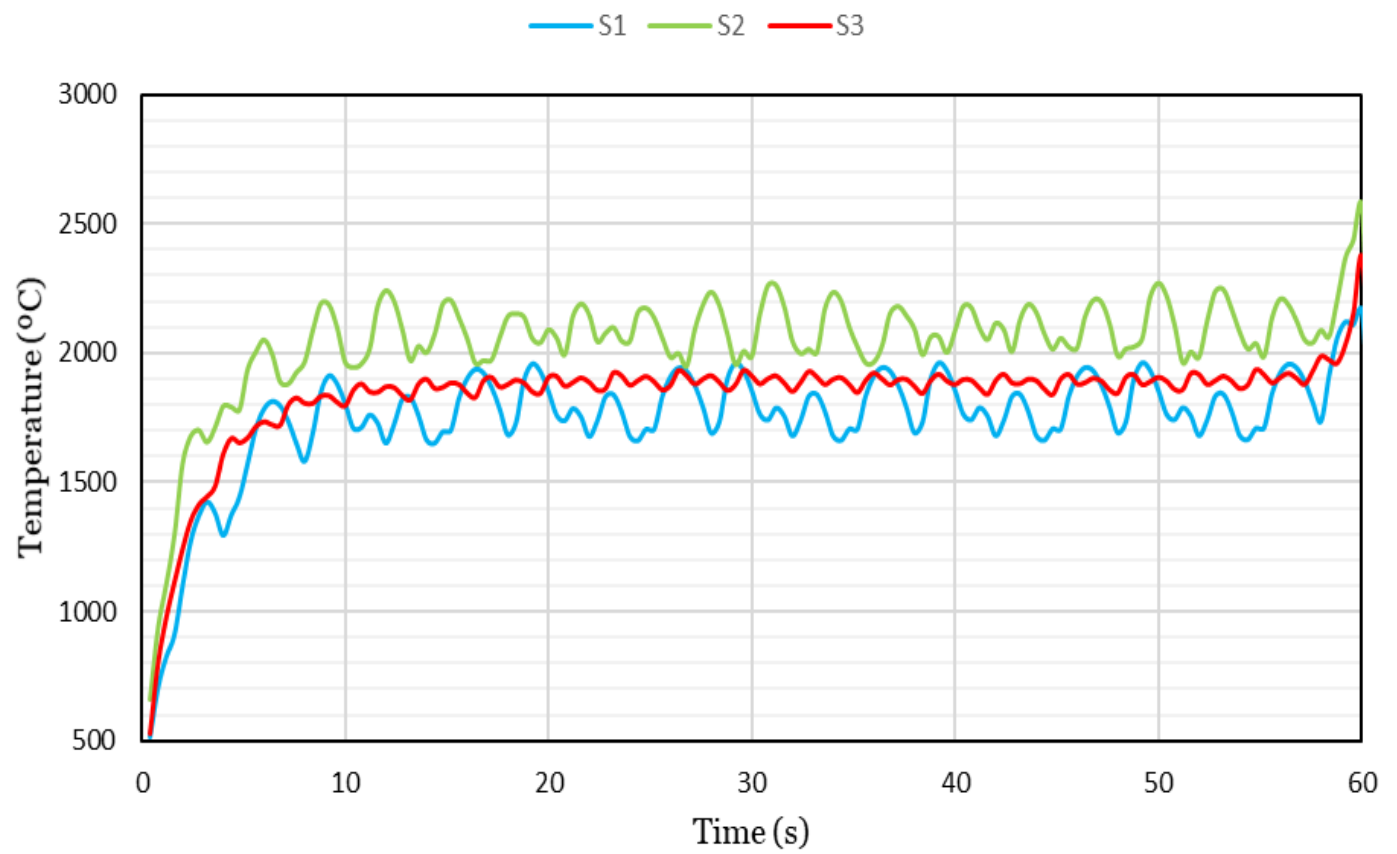

Fig. 10. Results for temperature time-history for MAG welding simulation

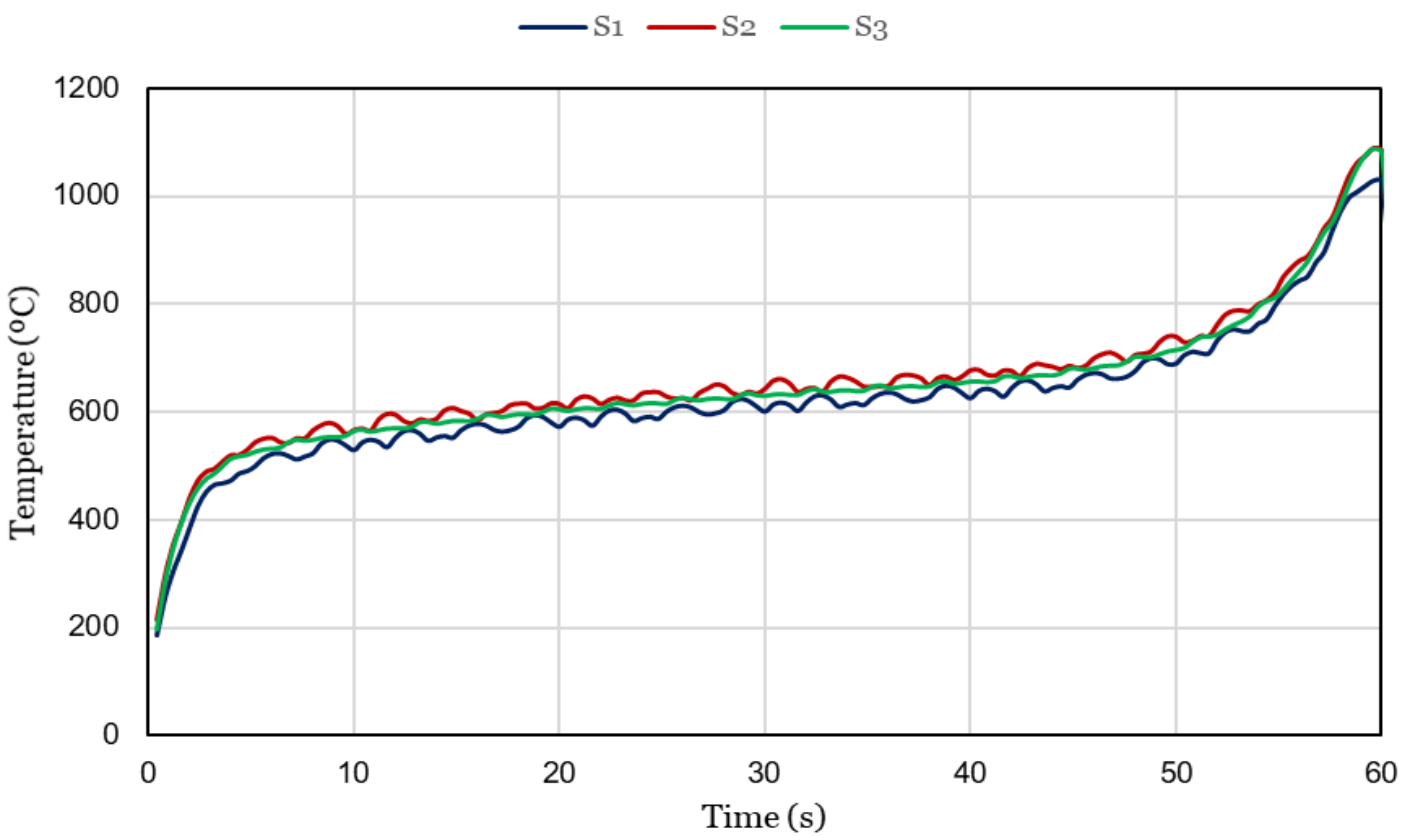

Fig. 11. Results for temperature time-history for TIG welding simulation

best adaptive behavior than compared to $\mathrm{S} 1$ and $\mathrm{S} 2$. The maximum temperature reached for the simulations were respectively, $1034^{\circ} \mathrm{C}, 1090^{\circ} \mathrm{C}$ and $1087^{\circ} \mathrm{C}$.

\subsection{Temperature Distribution and Metallurgical \\ Transformations}

In the temperature distributions, Fig. 12 illustrates the behavior at the end of time for MAG process and the Fig. 13 shows the metallurgical transformations in the weld pool.
The images reveal where the addition metal melts in fusion zone, the temperature reaches values at intervals of $2000^{\circ} \mathrm{C}$ $-1500^{\circ} \mathrm{C}$. In the Heat-Affected Zone (HAZ) there is a variation next to $600^{\circ} \mathrm{C}-1300^{\circ} \mathrm{C}$.

For the situation of A16082-T6 alloy, a greater thermal distribution is observed, situation explained because of the high coefficients of thermal conductivity and specific heat. Besides that, in Fig. 14 a melting temperature of approximately $630^{\circ} \mathrm{C}$ is also noted. The temperatures of the 


\section{International Journal of Applied Science and Engineering}

Marques et al., International Journal of Applied Science and Engineering, 18(5), 2021006

$\mathrm{HAZ}$ are consistent with that verified in the literature, with the phases of fusion (over $600^{\circ} \mathrm{C}$ ), solubilized region

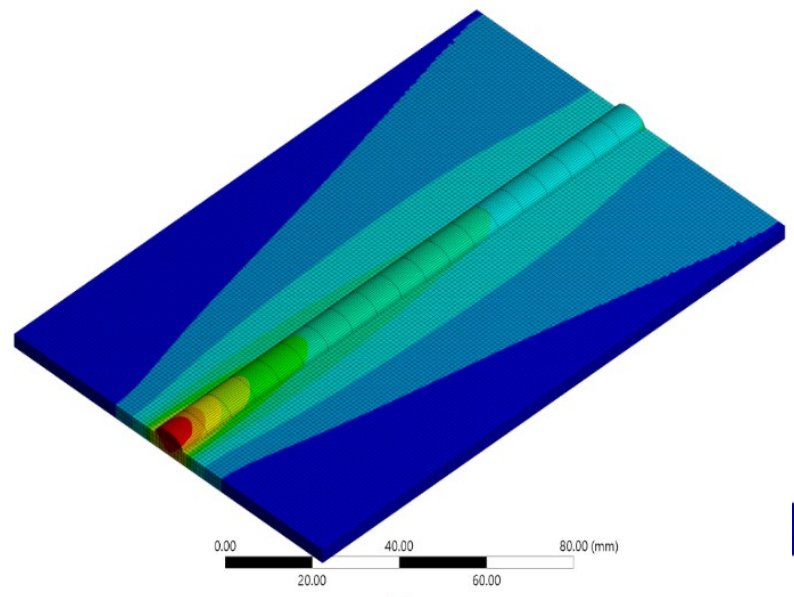

(between $600^{\circ} \mathrm{C}$ and $500^{\circ} \mathrm{C}$ ) and the over-aged region (at intervals of $500^{\circ} \mathrm{C}$ and $200^{\circ} \mathrm{C}$ ).

Fig. 12. Results for temperature time-history for MAG welding simulation
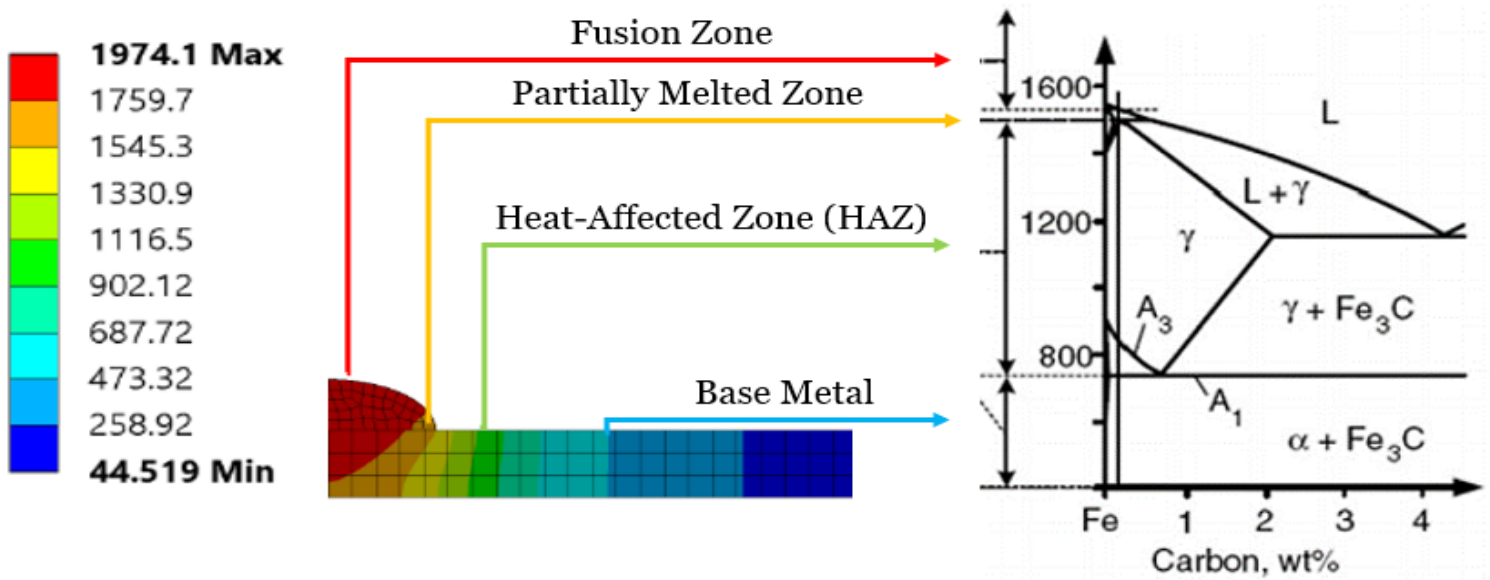

Fig. 13. S3 equivalence with metallurgical transformations for steel

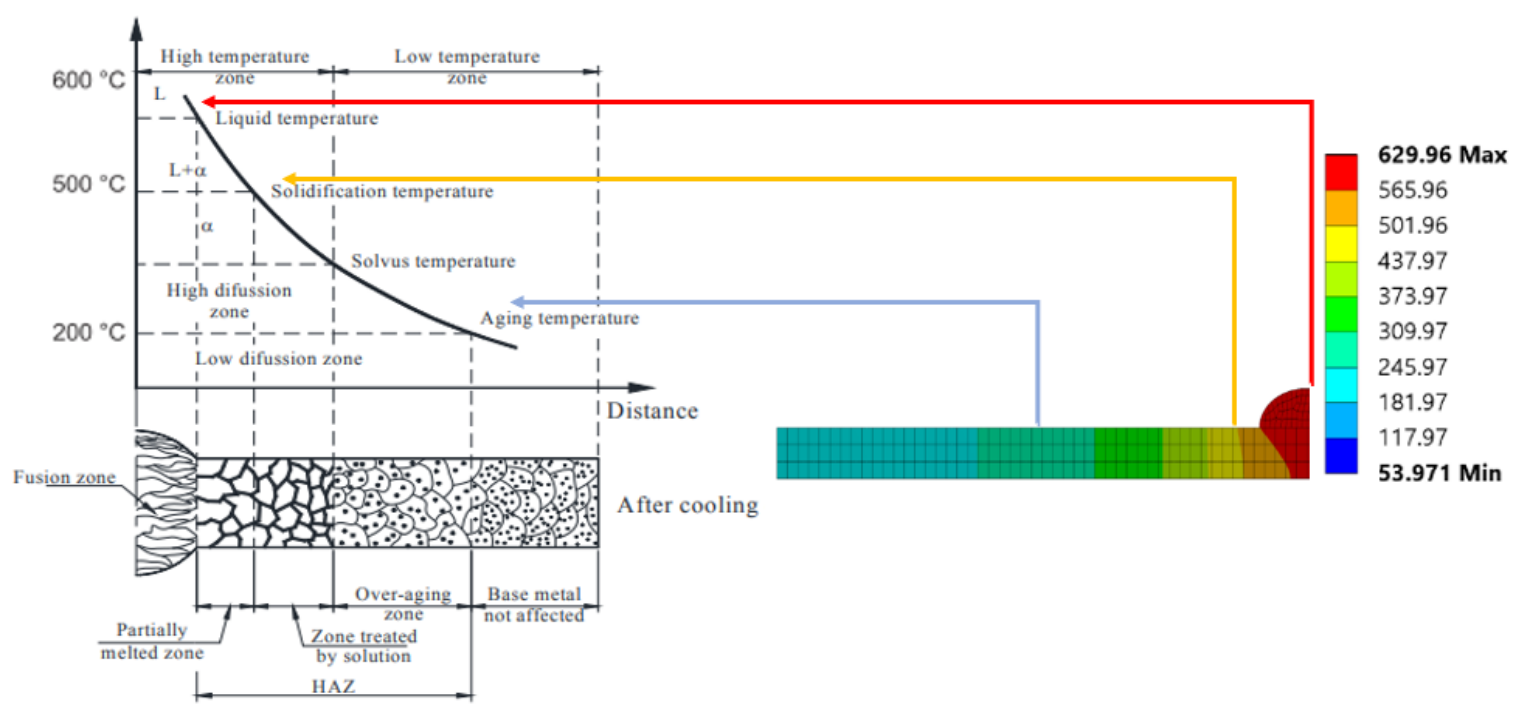

Fig. 14. S3 equivalence with metallurgical transformations for aluminium $6 X X X$ 


\section{International Journal of Applied Science and Engineering}

Marques et al., International Journal of Applied Science and Engineering, 18(5), 2021006

\subsection{Analytical-Numerical Evaluation}

In Fig. 15 are presented the graphical results for analytical and numerical responses, that it is possible to see in P1 a numerical behavior closest with adaptive function, which is not verified for Rosenthal equation that show a proximity only in the first 30 seconds. Moreover, in the time between 30 60 seconds, the adaptive solution presents values slightly higher than FEM.

For the P2 point, the numerical solution still shows some proximity to the adaptive function, however, at 30 to 60 seconds, the value found in the FEM is higher than adaptive function, a situation opposite to that occurred in P1. Another factor notorious is that Rosenthal solution becomes more divergent than the previous situation.
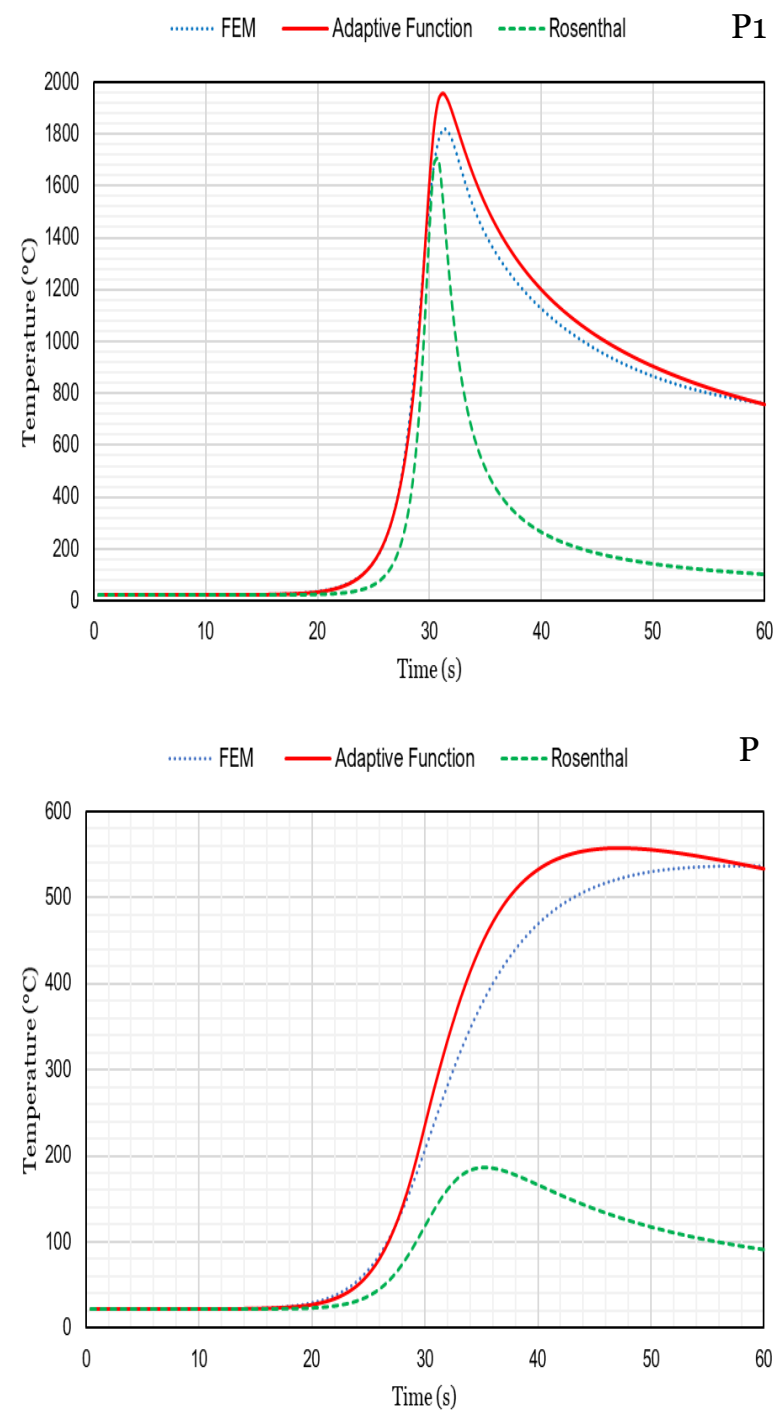

At points P3 and P4, the Rosenthal solution becomes practically outdated, observing only similarity between the FEM and adaptive function. It seen that in P3 the time interval (30-60 seconds) the adaptive function presents values higher than FEM, observing an encounter by the two functions only in the four final seconds. In P4, at interval of 30-60 seconds, the FEM curve becomes higher than the analytical function.

For the TIG welding, the points P1, P2, P3 and P4 are represented by the Fig. 16, where show in both points, the Rosenthal solution is totally at odd with the graphical response of the numerical and adaptive function solution. In $\mathrm{P} 1$, the adaptive function and FEM present a close encounter the interval of 25-32 seconds, and the highest temperature reached was in adaptive function $\left(615.48^{\circ} \mathrm{C}\right)$ compared to FEM $\left(614.28^{\circ} \mathrm{C}\right)$.
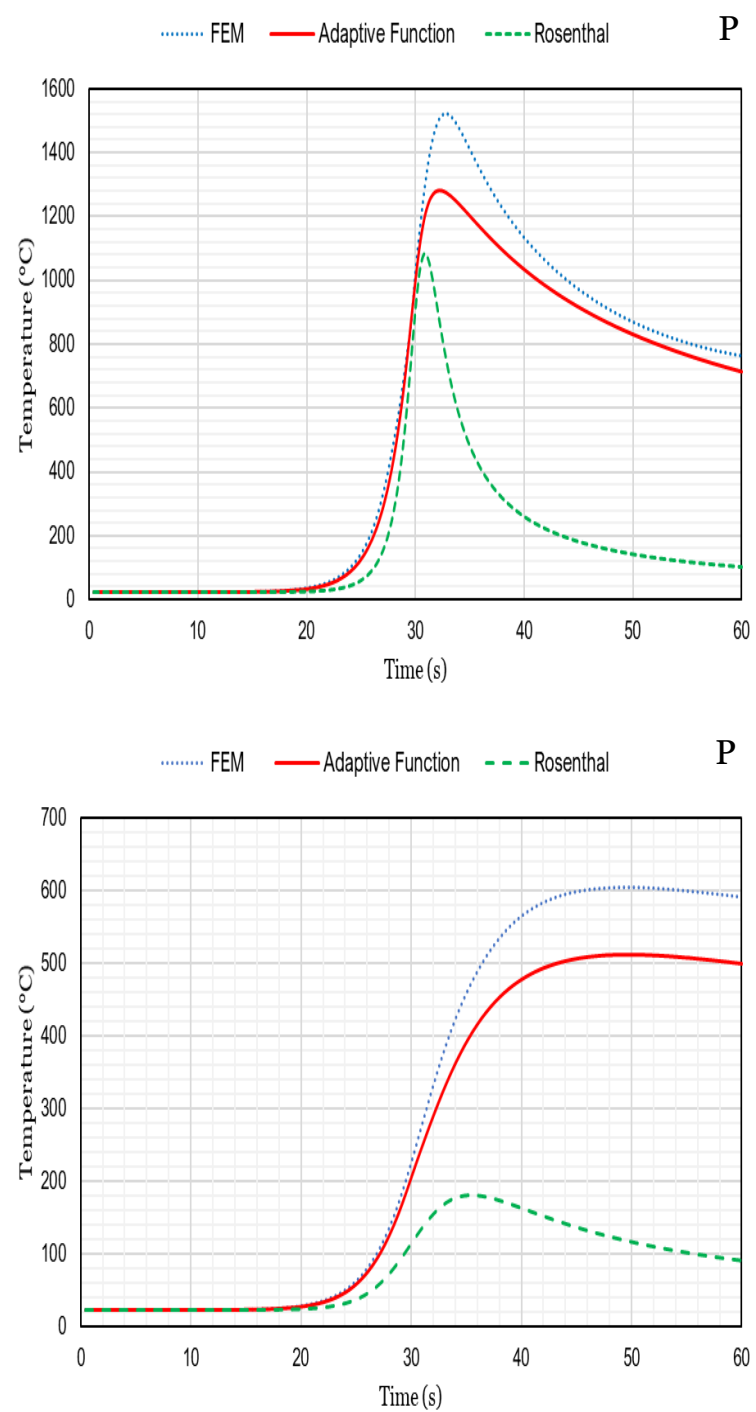

Fig. 15. Graphs of numerical and analytical responses for MAG welding 


\section{International Journal of Applied Science and Engineering}

Marques et al., International Journal of Applied Science and Engineering, 18(5), 2021006
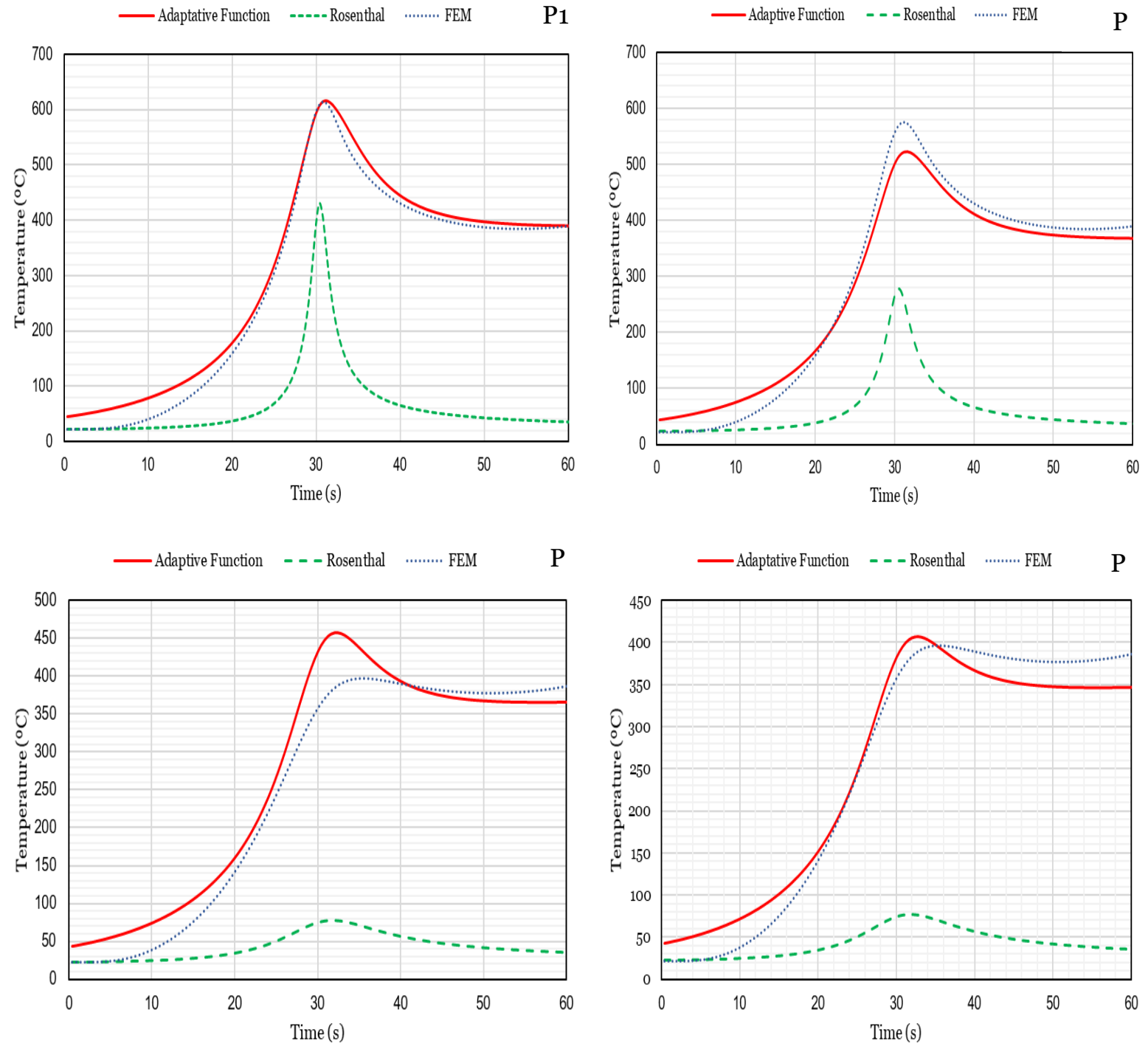

Fig. 15. Graphs of numerical and analytical responses for MAG welding

For P2, the FEM curves become higher than the adaptive solution between 30-60 seconds, and in P3 and P4, the adaptive function starts up than FEM, however, for the time of 40 s to P3 and 36s for P4 until the end, the numerical response becomes superior.

For these results, it is possible to assume some prepositions, being them; the points that correspond to the base metal surface, P1 and P3, in MAG situation, showed a behavior of the adaptive function higher than the FEM, nevertheless, the points correspond to the bottom of the base metal, P2 and P4, the FEM curve that showed the greatest behavior.

In the TIG results, the curves did not follow the same pattern seen in the MAG case, in all the responses the curves tend to invert positions, either at the beginning or at the end, with most of the encounters at the middle of the time.

\subsection{Errors and Comparisons}

To compare the thermal solution presented by the numerical extension tool, was calculated the relative error, taking into account the response of adaptive function as exact value, because as mentioned before, it is an experimentally validated method. Fig. 17 presents the relative error for points P1, P2, P3 and P4 for the MAG welding simulation.

The FEM showed the smallest errors for points P1 and P3, which corresponds to the surface of the base material, however, despite the values of P2 and P4 being slightly higher, the values are on average, bellow $10 \%$. In case of Rosenthal solutions, the error value was between 40-46\%.

For TIG welding, the results are presented in accordance with Fig. 18, that for the aluminum alloy the errors are greater than that of steel (an increase between $6 \sim 13 \%$ ). The 


\section{International Journal of Applied Science and Engineering}

Marques et al., International Journal of Applied Science and Engineering, 18(5), 2021006

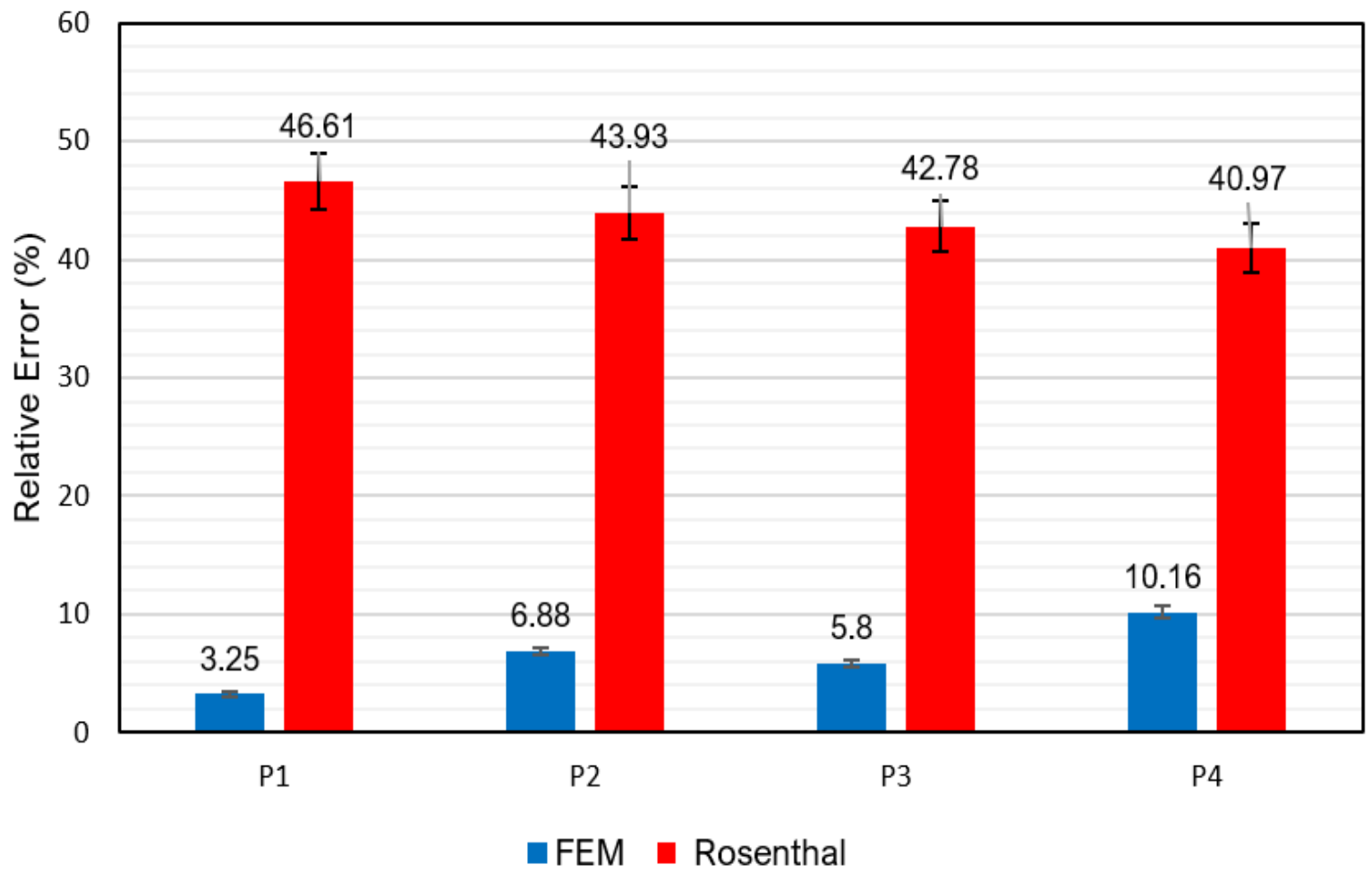

Fig. 17. Relative error of FEM and rosenthal with respect to adaptive function - MAG

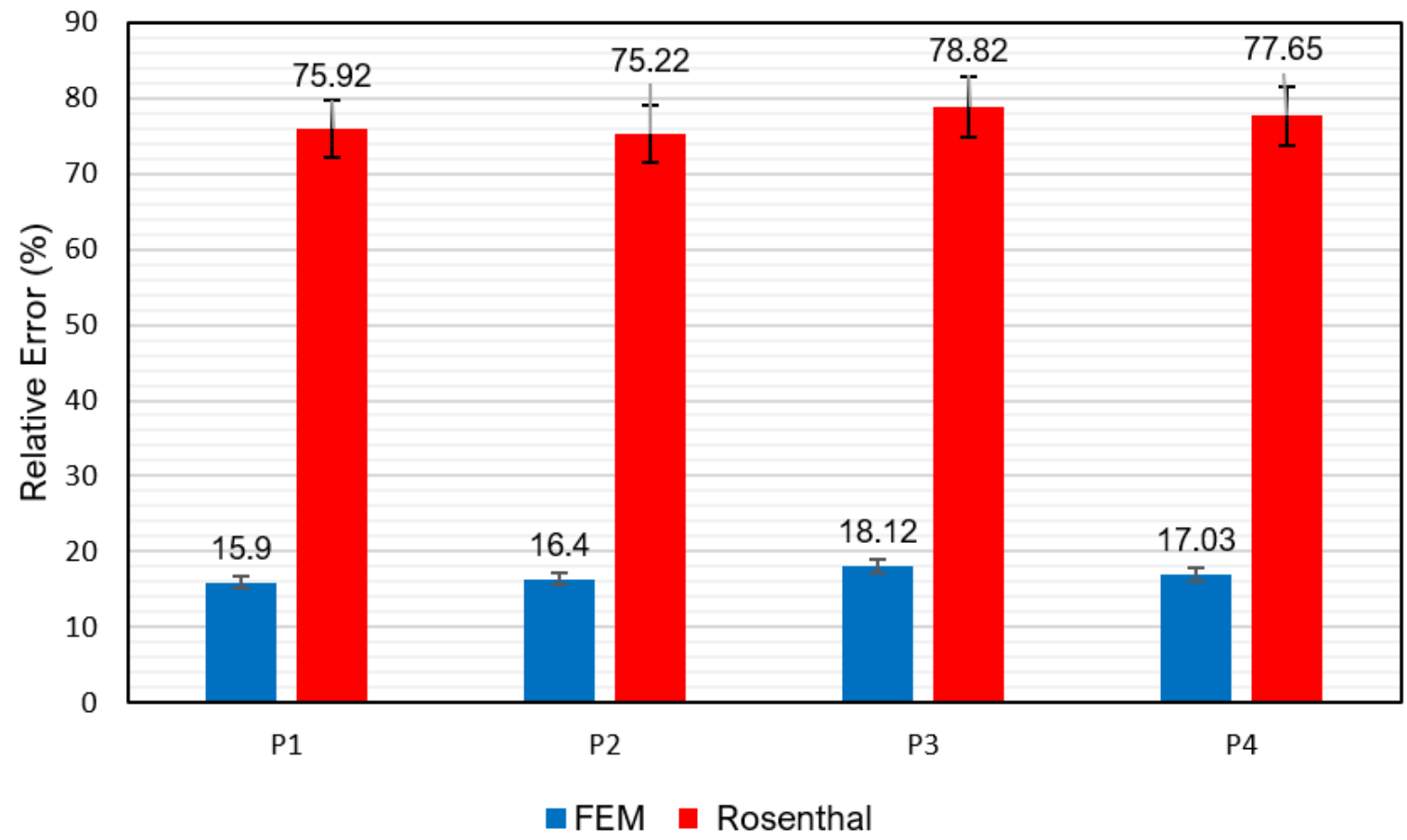

Fig. 18. Relative error of FEM and rosenthal with respect to adaptive function - TIG

points that showed the lowest errors for the FEM were P1 and P2. Furthermore, the Rosenthal equation increased the global error value when compared to MAG process, being $75 \%$ in TIG.

\section{CONCLUSION}

The ACT Moving Heat Source tool proved to be effective and with a relatively short calculation time, and its viability 
can be verified by comparing 4 points near the fusion line with the adaptive function analytical solution, which, in turn, has already it been experimentally valid;

Thermal simulations also showed results very close to reality in relation to the metallurgical transformations of the alloys. In addition, a lower error was found when it is intended to analyse points on the surface of the part, where P1 and P3 showed fewer errors than the points at the bottom of the part (P2 and P4).

In general, the finite element method applied to the simulation of MAG and TIG welding processes, presents a lower error value in the case of the simulation involving steel (error between $3 \sim 10 \%$ at points P1, P2, P3 and P4) than in aluminium alloy case (error between $15 \sim 18 \%$ at the same points).

Analytically, Rosenthal's mathematical solution did not prove to be a good comparative method, despite being one of the classic resources in the literature, recent solutions such as the one presented in this study showed better results.

Finally, when ACT compared to other numerical methods such as Goldak's semi-ellipsoidal and double-ellipsoidal the main advantages are; (i) There is no need to program an algorithm for modelling the fusion pool; (ii) Simple and intuitive interface, which saves time; (iii) Relatively low solution time; (iv) Metallurgical transformations well defined in the simulations. Regarding the disadvantages we can mention; (i) The other methods have more reliable results, since they have already been experimentally validated; (ii) needs a weld pool geometry well defined in the CAD model; (iii) Necessity to calculate thermal parameters to enter in the software.

However, for solutions that must be taking in account the cost and time, ACT has shown, for welding processes in steel and aluminum alloys, it can be a versatile and effective tool.

\section{ACKNOWLEDGMENT}

This research would like to thank the support of the double degree program by the Polytechnic Institute of Bragança and the Federal Center Celso Suckow da Fonseca (CEFET/RJ) as part of the master's project entitled "Estudo Numérico do Shot-Peening no Alívio de Tensões Residuais em Soldaduras de topo MAG e TIG". This work has been supported by FCT - Fundação para a Ciência e Tecnologia within the R\&D Units Project Scope: CIMO (UIDB/00690/2020).

\section{REFERENCES}

A. S. of M. (ASM) 1993. Welding, brazing, and soldering. Mechanical Design, 6, 155-155. https://doi.org/10.3138/9781487579890-121

Ambriz, R.R., Jaramillo, D. 2014. Mechanical behavior of precipitation hardened aluminum alloys welds. Light
Metal Alloys Applications, https://doi.org/10.5772/58418

(Fig.

1).

Amudha, A., Nagaraja, H.S., Shashikala, H.D. 2019. Finite element analysis of thermal residual stresses in SS309Mo and Inconel-625 multilayer weld deposition on low carbon steel. International Journal of Fatigue, 127, 338-344. https://doi.org/10.1016/j.ijfatigue.2019.06.014

Ansys. (n.d.) 2020. Ansys ACT The fastest, easiest way to tailor your simulation workflows. Retrieved April 15, from https://www.ansys.com/products/structures/ansysact

Asserin, O., Loredo, A., Petelet, M., Iooss, B. 2011. Global sensitivity analysis in welding simulations - What are the material data you really need? Finite Elements in Analysis and Design, 47, 1004-1016. https://doi.org/10.1016/j.finel.2011.03.016

B. S. E. N. 1999-1-2: (2007) 2007. Eurocode 9-Design of aluminium structures-Part 1-2: Structural fire design.

Bajpei, T., Chelladurai, H., Ansari, M.Z. 2016. Numerical investigation of transient temperature and residual stresses in thin dissimilar aluminium alloy plates. Procedia Manufacturing, 5, 558-567. https://doi.org/10.1016/j.promfg.2016.08.046

Balram, Y., Rajyalakshmi, G. 2019. Thermal fields and residual stresses analysis in TIG weldments of SS 316 and Monel 400 by numerical simulation and experimentation. Materials Research Express, 6. https://doi.org/10.1088/2053-1591/ab23cf

Bansal, A., Senthil Kumar, M., Shekhar, I., Chauhan, S., Bhardwaj, S. 2020. Effect of welding parameter on mechanical properties of TIG welded AA6061. Materials Today: Proceedings, (xxxx). https://doi.org/10.1016/j.matpr.2020.07.567

Cezario, C.A., Bork, B.C., Verardi, M., Santos, J.R. 2014. Robust electric machine design through multiphysics. Ansys Inc., VIII, 11-15.

Chiocca, A., Frendo, F., Bertini, L. 2019. Evaluation of heat sources for the simulation of the temperature distribution in gas metal arc welded joints. Metals, 9. https://doi.org/10.3390/met9111142

Darmadi, D.B., Kiet-Tieu, A., Norrish, J. 2014. A validated thermo mechanical FEM model of bead-on-plate welding. International Journal of Materials and Product Technology, 48, 146-166. https://doi.org/10.1504/IJMPT.2014.059047

Darmadi, D.B., Norrish, J., Tieu, A.K. 2011. Analytic and finite element solutions for temperature profiles in welding using varied heat source models. World Academy of Science, Engineering and Technology, 81, 154-162.

Deng, D., Murakawa, H., Liang, W. 2007. Numerical simulation of welding distortion in large structures. Computer Methods in Applied Mechanics and Engineering, 196, 4613-4627. https://doi.org/10.1016/j.cma.2007.05.023

E. N. 1993-1-2: (2005) 2005. Eurocode 3-Design of steel structures-Part 1-2: General Rules-Structural fire design. 
Feng, Z. 2005. Processes and mechanisms of welding residual stress and distortion. Elsevier.

Friedman, E. 1975. Thermomechanical analysis of the welding process using the finite element method. Journal of Pressure Vessel Technology, Transactions of the ASME, 97, 206-213. https://doi.org/10.1115/1.3454296

Ganesh, K.C., Vasudevan, M., Balasubramanian, K.R., Chandrasekhar, N., Mahadevan, S., Vasantharaja, P., Jayakumar, T. 2014. Modeling, prediction and validation of thermal cycles, residual stresses and distortion in type 316 LN stainless steel WELD joint made by TIG welding process. Procedia Engineering, 86, 767-774. https://doi.org/10.1016/j.proeng.2014.11.096

Goldak, J., Chakravarti, A., Bibby, M. 1984. A new finite element model for welding heat sources. Metallurgical Transactions B, 15, 299-305.

Guilherme, L.H., Benedetti, A.V., Fugivara, C.S., Magnabosco, R., Oliveira, M.F. 2020. Effect of MAG welding transfer mode on sigma phase precipitation and corrosion performance of 316L stainless steel multi-pass welds. Journal of Materials Research and Technology, 9, 10537-10549. https://doi.org/10.1016/j.jmrt.2020.07. 039

Kik, T., Górka, J. 2019. Numerical simulations of laser and hybrid S700MC T-joint welding. Materials, 12. https://doi.org/10.3390/ma12030516

Knoedel, P., Gkatzogiannis, S., Ummenhofer, T. 2017. Practical aspects of welding residual stress simulation. Journal of Constructional Steel Research, 132, 83-96. https://doi.org/10.1016/j.jcsr.2017.01.010

Komanduri, R., Hou, Z.B. 2000. Thermal analysis of the arc welding process: Part I. General solutions. Metallurgical and Materials Transactions B: Process Metallurgy and Materials Processing Science, 31, 1353-1370. https://doi.org/10.1007/s11663-000-0022-2

Kumar, P., Kumar, R., Arif, A., Veerababu, M. 2020. Investigation of numerical modelling of TIG welding of austenitic stainless steel (304L). Materials Today: Proceedings, 27, 1636-1640. https://doi.org/10.1016/j.matpr.2020.03.544

Kumar, P., Sinha, A.N. 2018. Studies of temperature distribution for laser welding of dissimilar thin sheets through finite element method. Journal of the Brazilian Society of Mechanical Sciences and Engineering, 40. https://doi.org/10.1007/s40430-018-1380-5

Lahtinen, T., Vilaça, P., Infante, V. 2019. Fatigue behavior of MAG welds of thermo-mechanically processed $700 \mathrm{MC}$ ultra high strength steel. International Journal of Fatigue, 126, 62-71. https://doi.org/10.1016 /j.ijfatigue.2019.04.034

Nasiri, M.B., Enzinger, N. 2019. Powerful analytical solution to heat flow problem in welding. International Journal of Thermal Sciences, 135, 601-612. https://doi.org/10.1016/j.ijthermalsci.2018.08.003

Nguyen, N.T., Ohta, A., Matsuoka, K., Suzuki, N., Maeda, Y. 1999. Analytical solutions for transient temperature of semi-infinite body subjected to 3-D moving heat sources. Welding Journal (Miami, Fla), 78.

Rosenthal, D. 1946. The theory of moving sources of heat and its application of metal treatments. Transactions of ASME, 68, 849-866.

Vairamani, V., Mohan, N., Venkatesh, Karthikeyan, S.K., Sakthivel, M. 2020. Optimization and microstructure analysis of Corten steel joint in mag welding by post heat treatment. Materials Today: Proceedings, 21, 673-680. https://doi.org/10.1016/j.matpr.2019.06.737

Velaga, S.K., Ravisankar, A. 2017. Finite element based parametric study on the characterization of weld process moving heat source parameters in austenitic stainless steel. International Journal of Pressure Vessels and Piping, 157, 63-73. https://doi.org/10.1016/j.ijpvp.2017.09.001

Venkatkumar, D., Ravindran, D. 2019. Effect of boundary conditions on residual stresses and distortion in 316 stainless steel butt welded plate. High Temperature Materials and Processes, 38, 827-836. https://doi.org/10.1515/htmp-2019-0048

Vicente, T.A., Oliveira, L.A., Correa, E.O., Barbosa, R.P., Macanhan, V.B.P., de Alcântara, N.G. 2018. Stress corrosion cracking behaviour of dissimilar welding of AISI $310 \mathrm{~S}$ austenitic stainless steel to 2304 duplex stainless steel. Metals, 8. https://doi.org/10.3390/ met8030195

Wang, L., Chen, J., Wu, C., Luan, S. 2020. Numerical analysis of arc and droplet behaviors in gas metal arc welding with external compound magnetic field. Journal of Materials Processing Tech., 116638. https://doi.org/10.1016/j.jmatprotec.2020.116638

Wang, X., Xiao, Y., Gao, N., Liang, L., Lu, C., Jiang, H. 2019. A semi-analytical solution of three-dimensional transient temperature field for a uniform plate subjected to Gaussian-distribution laser heat source. Thermal Science, 268-268. https://doi.org/10.2298/ tsci190102268w

Winczek, J. 2017. Modeling of temperature field during multi-pass gmaw surfacing or rebuilding of steel elements taking into account the heat of the deposit metal. Applied Sciences (Switzerland), 7. https://doi.org/ 10.3390/app7010006

Zuo, S., Wang, Z., Wang, D., Du, B., Cheng, P., Yang, Y. Lang, N. 2020. Numerical simulation and experimental research on temperature distribution of fillet welds. Materials, 13. https://doi.org/10.3390/ma13051222 